\title{
Evaluation of Virulence Factors and Antibiotic Sensitivity Pattern of Escherichia Coli Isolated from Extraintestinal Infections
}

\author{
Ritu Vaish ${ }^{1}$, MSS Pradeep ${ }^{2}$, CR Setty ${ }^{2}$, Venkataramana Kandi ${ }^{1}$ \\ 1. Department of Microbiology, Prathima Institute of Medical Sciences 2. Department of Microbiology, \\ Dr. Pinnamaneni Siddhartha Institute of Medical Sciences and Research Foundation
}

$\square$ Corresponding author: Venkataramana Kandi, ramana20021@gmail.com

Disclosures can be found in Additional Information at the end of the article

\section{Abstract}

\section{Introduction}

Identification of virulence determinants among the clinically isolated microorganisms assumes greater significance in the patient management perspective. Among the hospitalized patients, extremes of age groups (neonatal and geriatric age patients), patients who are debilitated due to other associated medical conditions, patients taking immunosuppressive therapy, and patients undergoing major surgeries are prone to infections with previously nonpathogenic or opportunistic pathogens. Screening of the pathogenic potential of such bacteria and identifying their virulence factors and antimicrobial susceptibility patterns could be instrumental in better patient care and management.

\section{Materials \& methods}

In this study, we evaluated the virulence determinants and antimicrobial susceptibility patterns of 100 clinical isolates of $E$. coli collected from extraintestinal infections and 50 control strains of E. coli. Hemolysin production, serum resistance, cell surface hydrophobicity, and gelatinase production were tested using standard laboratory procedures.

\section{Results}

Results showed that $E$. coli strains have a variable pattern of virulence markers that included hemolysin production (9\%), cell surface hydrophobicity (9\%), serum resistance (93\%), and gelatinase production (2\%). Antimicrobial susceptibility testing revealed a higher rate of resistance against cephalothin (84\%) and ampicillin (98\%). Susceptibility to amikacin (80\%) and co-trimoxazole (47\%) was variable and none of the test strains revealed resistance to imipenem. The control strains in contrast exhibited fewer virulence factors and the least

Received 04/04/2016 Review began 04/19/2016 Review ended 04/24/2016 Published 05/09/2016

C) Copyright 2016

Vaish et al. This is an open access article distributed under the terms of the Creative Commons Attribution License CC-BY 3.0., which permits unrestricted use, distribution, and reproduction in any medium, provided the original author and source are credited. resistance to antibiotics.

\section{Conclusion}

In conclusion, the study results revealed that $E$. coli isolated from extraintestinal infections had demonstrated greater virulence and higher resistance to antibiotics as compared to the $E$. coli strains isolated from healthy individuals.

Categories: Infectious Disease, Epidemiology/Public Health

Keywords: escherichia coli, virulence determinants, antimicrobial susceptibility patterns, hemolysin 
production, cell surface hydrophobicity, serum resistance, gelatinase production, extraintestinal infections

\section{Introduction}

Escherichia coli (E. coli) is a gram negative and rod-shaped bacteria belonging to the phylum Proteobacteria and family Enterobacteriaceae. They are present in the intestinal tract of both human and animals as a commensal [1]. Although most E. coli species are harmless, few strains have been associated with a variety of human infections that include and are not limited to urinary tract infections, wound infections, bacteremia, meningitis, and other soft tissue infections [2-3]. E. coli uses its virulence factors and the debilitated condition of the individuals and could be responsible for mild to invasive infections including hospital-acquired infections.

Among the various infections caused by $E$. coli, urinary tract infections (UTI) assume greater significance as observed by the fact that $E$. coli is responsible for more than $90 \%$ of UTI cases. Due to its easy transmissibility and the presence of virulence determinants, the normal human and animal intestinal colonizers invade the urinary tract through the ascending route and cause UTI [4].

As with many other microbial infections, human clinical isolates of $E$. coli have a relatively high potential for developing antibiotic resistance. Occurrence and spread of extended spectrum beta-lactamase (ESBL) and carbapenemase producing E. coli strains should be considered as a serious concern. Infections caused by E. coli NDM-1 gene (New Delhi metallo beta-lactamase) producers and the multi-drug resistant strains are a threat in the hospital as infections caused by such bacteria are difficult to treat. Their ubiquitous nature and their versatile habitats; their presence in human and animal as commensals, isolated from the environment (water); and their pathogenic potential to cause various infections usually among immunocompromised people makes E. coli a true opportunistic pathogen [5].

E. coli is a gram-negative, rod-shaped, motile, non-sporing, lactose fermenting and facultatively anaerobic bacterium belonging to the genus Escherechia. E. coli is present as a normal colonizer in the lower intestinal tract of humans benefiting the host by producing vitamins that include vitamin K. E. coli are usually transmitted to humans through feco-oral route and are responsible for diarrhea owing to the presence of various enterotoxins. The ability of $E$. coli to cause extraintestinal infections depends largely on a combination of several virulence factors, which help the $E$. coli survive under adverse conditions present in those sites [2].

The virulence factors contributing to the colonization and pathogenicity of E. coli include adhesins (function like hemagglutinin by helping to adhere uroepithelial cells), serum resistance, hemolysin production, cell surface hydrophobicity, resistance to phagocytosis, production of cytotoxic necrotizing factor, $\mathrm{K} 1$ antigen, siderophore, gelatinase production, and others [2]. The present study aims to evaluate the virulence determinants (hemolysin production, serum resistance, cell surface hydrophobicity, and gelatinase production) demonstrated by the clinical isolates of $E$. coli responsible for extraintestinal infections and their antimicrobial susceptibility patterns.

\section{Materials And Methods}

This study included 100 isolates of $E$. coli collected from extraintestinal infections from both inpatients and outpatients attending Dr. Pinnamaneni Siddhartha Institute of Medical Sciences and Research Foundation (Dr. PSIMS \& RF) and was performed in the department of microbiology, between August 2011 and December 2012. Informed consent was obtained from the patients for this study. 
Specimens collected included urine, pus, blood, cerebrospinal fluid, sputum, and synovial fluid. The samples were processed using standard bacteriological procedures and isolates were identified based on gram staining, colony morphology on blood agar, MacConkey agar, and by standard and conventional biochemical tests. Further, all the strains were assessed for antibiotic susceptibility patterns against commonly used antibiotics. Fifty isolates of $E$. coli from stool samples from apparently healthy individuals who had visited the hospital for routine health checkup formed the control group. The isolates were maintained by inoculating onto semi solid nutrient agar butts and stored at $2-4^{\circ} \mathrm{C}$ until further detection.

\section{Detection of virulence factors}

Hemolysin production: Hemolysin is a cytolytic toxin, a protein secreted by some E. coli isolates, which is also referred to as alpha-hemolysin. Production of alpha-hemolysin was demonstrated by using blood agar plate hemolysis method. Clinical strains of $E$. coli were inoculated onto $5 \%$ sheep blood agar and incubated overnight at $35^{\circ} \mathrm{C}$. Hemolysin production was detected by the presence of a zone of complete clearance of erythrocytes around the colony as observed against transmitted light [6-7].

Cell surface hydrophobicity (CSH)/Salt aggregation test (SAT): Bacteria were tested for their hydrophobic property by using different molar concentrations of ammonium sulphate. E. coli grown on nutrient agar plates were inoculated into $1 \mathrm{ml}$ of phosphate buffered saline (PBS) at $\mathrm{pH}$ 6.8. The turbidity was matched with McFarland standard 6-7 to finally give a colony count of $5 \times 10^{9}$ colonies $/ \mathrm{ml}$. Different molar concentrations of ammonium sulphate $(0.625 \mathrm{M}, 1.25 \mathrm{M}$, and $2.5 \mathrm{M}$ ) were prepared. On a clean and grease-free glass slide, $10 \mu \mathrm{l}$ of bacterial suspension prepared in PBS was mixed with equal volumes of ammonium sulphate solution at different molarity and rocked for a minute to observe for clumping. E. coli strains that had SAT value $\leqslant$ 1.25 M were considered hydrophobic and those which demonstrated aggregates with salt particles by forming clumps were considered as positive for cell surface hydrophobicity. The highest dilution of ammonium sulphate solution producing a visible clumping was treated as a positive titer for salt aggregation test [8-9].

Serum resistance: Overnight growth of $E$. coli on 5\% sheep blood agar was suspended in PBS to produce a count of $2.5 \times 10^{4} \mathrm{cfu} / \mathrm{ml} .10 \mu \mathrm{l}$ of the suspension was then inoculated on $5 \%$ sheep blood agar plates. In a test tube $50 \mu \mathrm{l}$ of bacterial suspension is mixed with $50 \mu$ l of human serum and is incubated for a period of 180 minutes. After incubation $10 \mu$ of this suspension was inoculated on $5 \%$ blood agar and incubated overnight at $37^{\circ} \mathrm{C}$ and the viable count was determined. Susceptibility of bacteria to serum bactericidal activity was expressed as the percentage of bacteria surviving after 180 minutes in relation to the original count of bacteria determined at 0 minutes. Strains were considered as serum sensitive if the viable count dropped by $1 \%$ of the initial value and resistant if $>90 \%$ of organisms survived after 180 minutes [10-11].

Gelatinase production/protease activity: Gelatinase activity was demonstrated using gelatin agar. The gelatin agar plate was inoculated with $E$. coli and was incubated at $37^{\circ} \mathrm{C}$ for 24 hours. After incubation, the plates were flooded with mercuric chloride solution. Development of the zone of opacity surrounding the colonies was considered positive for gelatinase production [2].

Antibiotic susceptibility testing: The antibiotic susceptibility testing was performed using Kirby-Bauer disk diffusion method in accordance with Clinical and Laboratory Standards Institute (CLSI) guidelines. The antibiotic discs (Hi Media, Mumbai, India) tested included ampicillin $(10 \mu \mathrm{g})$, cephalothin $(30 \mu \mathrm{g})$, ceftriaxone $(30 \mu \mathrm{g})$, gentamicin $(10 \mu \mathrm{g})$, amikacin (30 $\mu \mathrm{g})$, nitrofurantoin $(300 \mu \mathrm{g})$, norfloxacin $(10 \mu \mathrm{g})$, ciprofloxacin $(5 \mu \mathrm{g})$, cotrimoxazole $(1.25 /$ $23.75 \mu \mathrm{g})$ and imipenem $(10 \mu \mathrm{g})[12]$. 


\section{Cureus}

After overnight incubation at $37^{\circ} \mathrm{C}$, the diameter of the zone of inhibition around the antibiotic disk was measured in millimeter scale from the under-surface of the plate. Depending on the standard zone sizes for each antibiotic, the result was interpreted as sensitive, intermediate, or resistant.

\section{Results}

Out of 100 isolates of $E$. coli, 65 strains were isolated from urine, 29 from pus, one from liver abscess, two from endotracheal secretion, and one from gastric lavage as shown in Table 1.

Nature of Specimen

Urine

Vaginal swab

Liver abscess aspirate

Pus swab

Endotracheal tube

Gastric lavage

Total

\section{Number}

65

2

1

29

2

1

100

\section{TABLE 1: Specimen-wise Distribution of Isolates}

The underlying medical conditions identified among the subjects' group from whom the extraintestinal isolates of $E$. coli were collected included patients suffering from diabetes mellitus, uterine prolapse, liver abscess, hypertension, stress, urinary incontinence, retention of urine, cerebrovascular accident (CVA) with hemiparesis, cancer of cervix, uterine fibroids, catheterization, benign prostatic hypertrophy, hypospadias, and dysplastic kidney.

Among the virulence factors studied, hemolysin production (9\%), cell surface hydrophobicity (9\%), serum resistance (93\%), and gelatinase production (2\%) were noted for all the isolates as detailed in Table 2. 


\section{Cureus}

\begin{tabular}{|c|c|c|c|c|}
\hline Specimen Source & $\begin{array}{l}\text { Hemolysin } \\
\text { Production }\end{array}$ & $\begin{array}{l}\text { Cell surface } \\
\text { Hydrophobicity }\end{array}$ & $\begin{array}{l}\text { Serum } \\
\text { Resistance }\end{array}$ & $\begin{array}{l}\text { Gelatinase } \\
\text { Production }\end{array}$ \\
\hline Pus & 1 & 4 & 25 & 1 \\
\hline Urine & 7 & 5 & 62 & 1 \\
\hline High vaginal swab & 1 & 0 & 2 & 0 \\
\hline $\begin{array}{l}\text { Liver abscess } \\
\text { aspirate }\end{array}$ & 0 & 0 & 1 & 0 \\
\hline ET tube & 0 & 0 & 2 & 0 \\
\hline Gastric lavage & 0 & 0 & 1 & 0 \\
\hline Total & $9(9 \%)$ & $9(9 \%)$ & $93(93 \%)$ & $2(2 \%)$ \\
\hline
\end{tabular}

TABLE 2: Virulence Factors Studied in Different Clinical and Control Isolates

The most common virulence factor identified was serum resistance (93\%). Cell surface hydrophobicity and gelatinase production were observed in the least number of strains as shown in Table 2. Comparison of the virulence determinants demonstrated among the test groups and the controls revealed that hemolysin production was observed in $47 \%$ of $E$. coli isolates in the study group, whereas all control groups isolates were negative for hemolysin production as shown in Figure 1. 


\section{Cureus}

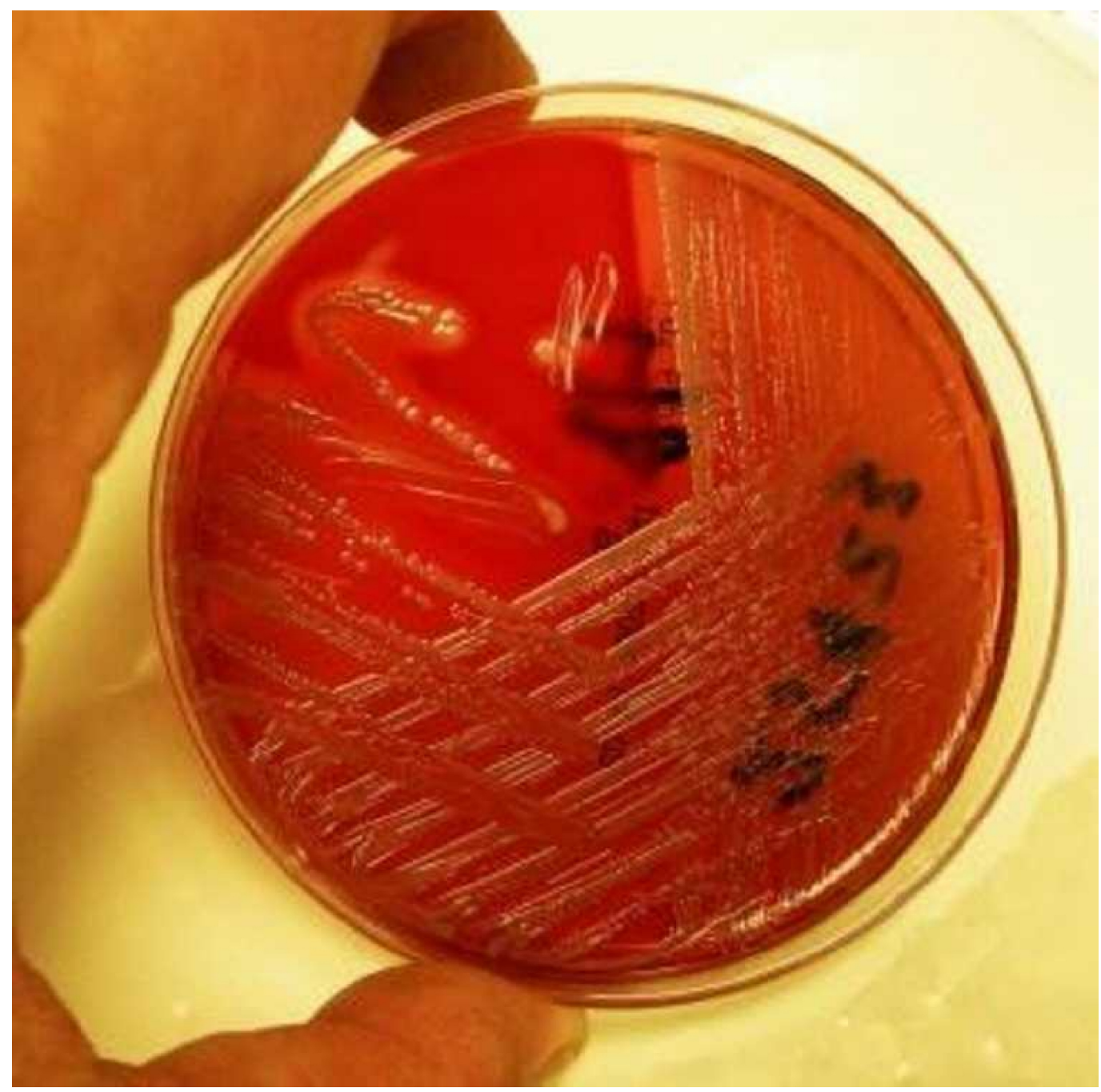

FIGURE 1: Picture Depicting Hemolytic activity on Blood Agar

In the study group, cell surface hydrophobicity was observed in $9 \%$ of $E$. coli isolates, whereas in controls 10 (20\%) strains exhibited cell surface hydrophobicity. In the study group, 93\% of $E$. coli isolates were serum resistant and only two (4\%) isolates showed serum resistance as shown in Figure 2. 


\section{Cureus}

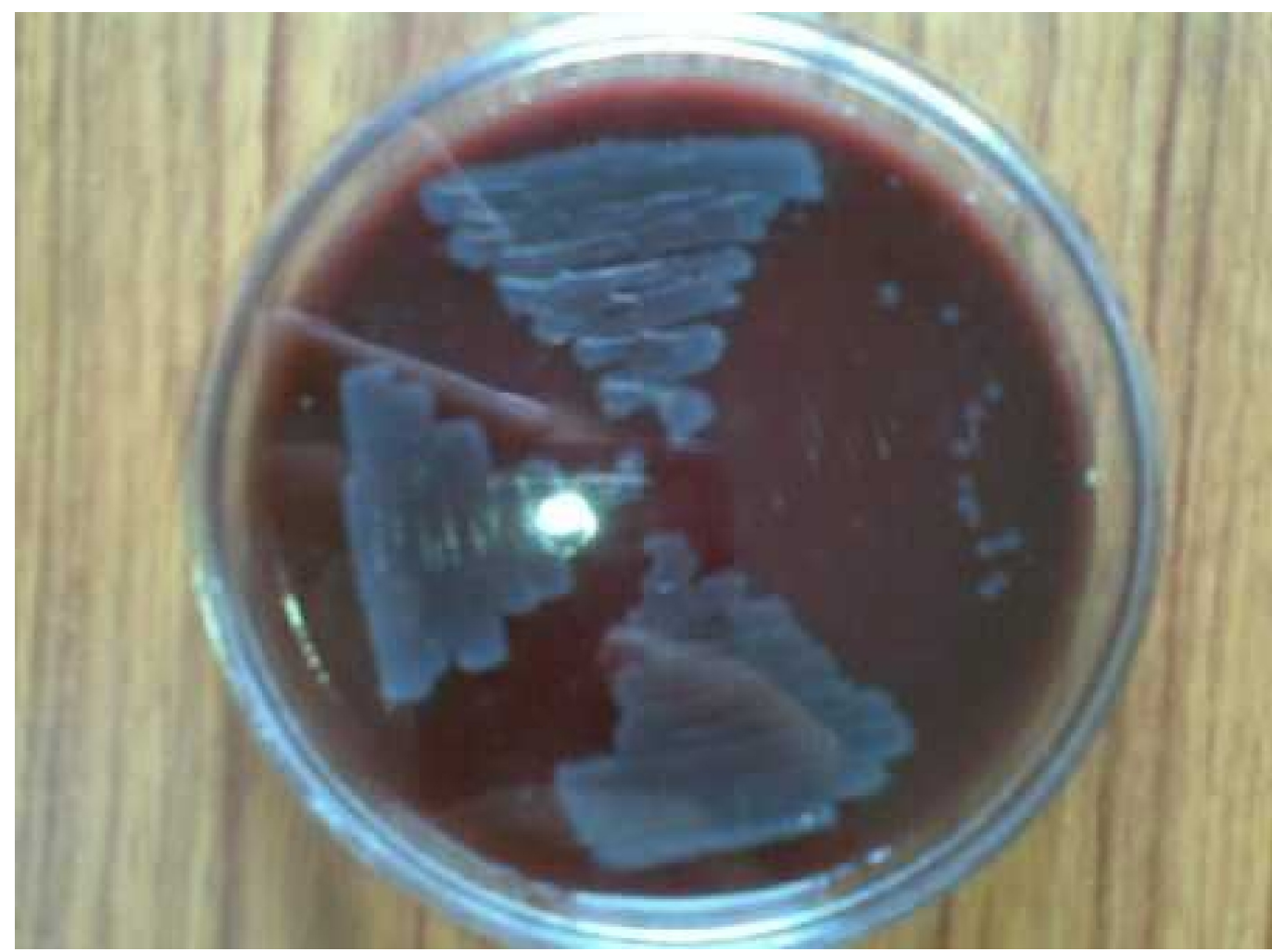

FIGURE 2: Serum Sensitivity and Resistant Pattern of E. coli

The study also showed that $2 \%$ of $E$. coli isolates were gelatinase producers and none among the control group demonstrated this virulence factor as shown in Table 3 and Figure 3.

\begin{tabular}{|c|c|c|c|c|c|c|c|c|}
\hline \multirow[t]{2}{*}{ Isolates } & \multicolumn{2}{|c|}{ Hemolysin Production } & \multicolumn{2}{|c|}{$\begin{array}{l}\text { Cell Surface } \\
\text { Hydrophobicity }\end{array}$} & \multicolumn{2}{|c|}{ Serum Resistance } & \multicolumn{2}{|c|}{ Gelatinase Production } \\
\hline & $\begin{array}{l}\text { Positive n } \\
\text { (\%) }\end{array}$ & $\begin{array}{l}\text { Negative n } \\
(\%)\end{array}$ & $\begin{array}{l}\text { Positive n } \\
\text { (\%) }\end{array}$ & $\begin{array}{l}\text { Negative n } \\
\text { (\%) }\end{array}$ & $\begin{array}{l}\text { Positive n } \\
\text { (\%) }\end{array}$ & $\begin{array}{l}\text { Negative n } \\
(\%)\end{array}$ & $\begin{array}{l}\text { Positive n } \\
\text { (\%) }\end{array}$ & $\begin{array}{l}\text { Negative n } \\
\text { (\%) }\end{array}$ \\
\hline Test strains & $9(9)$ & 91 (91) & $9(9)$ & $91(91)$ & $93(93)$ & $7(7)$ & $2(2)$ & $98(98)$ \\
\hline $\begin{array}{l}\text { Control } \\
\text { isolates }\end{array}$ & $0(0)$ & 50 (100) & $10(20)$ & $40(80)$ & $2(4)$ & $48(96)$ & $0(0)$ & $50(100)$ \\
\hline
\end{tabular}

TABLE 3: Comparison of Various Virulence Factors in Both Test Isolates and the Controls 


\section{Cureus}

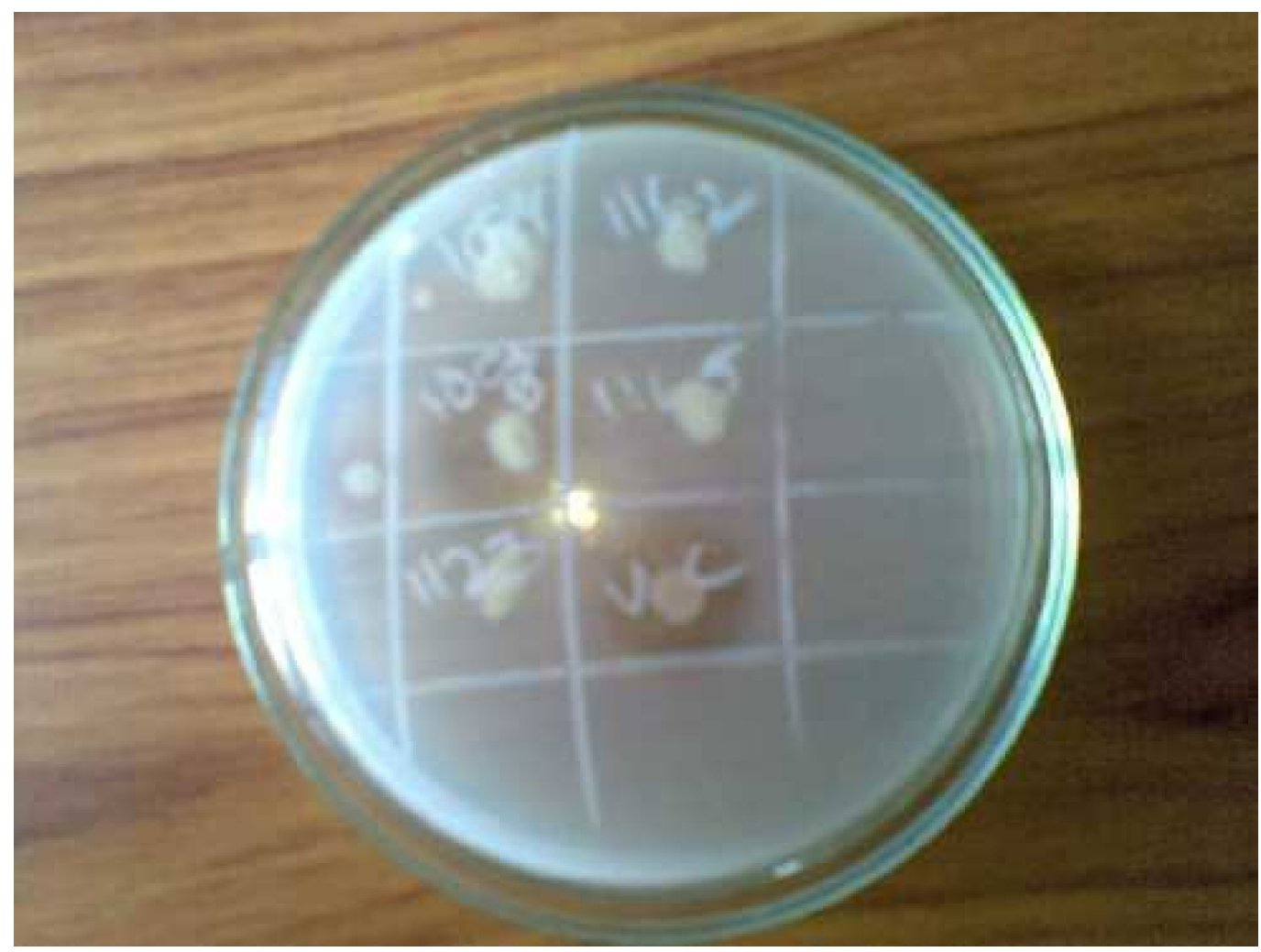

FIGURE 3: Gelatinase Production as Evidenced by Clearance Surrounding the Colonies

Out of $100 \mathrm{E}$. coli included in the study only 65 strains were isolated from urine and among these isolates 62 isolates were found to be susceptible to nitrofurantoin and three showed resistance. Among test strains majority of $E$. coli isolates (80\%) were sensitive to amikacin whereas only $47 \%$ of isolates were susceptible to co-trimoxazole. Susceptibility to ciprofloxacin/norfloxacin (22\%) and ceftriaxone (28\%) was noted to be low. A higher rate of resistance was observed against cephalothin (84\%) and ampicillin (98\%). None of the isolates from test strains showed resistance to imipenem. Among control strains included in the study, 46 (92\%) isolates showed sensitivity to amikacin, 28 (56\%) isolates revealed sensitivity to ciprofloxacin, and all isolates were sensitive to imipenem. The detailed antibiotic susceptibility profile of all the strains tested is shown in Table 4 and demonstrated in Figure 4. 


\section{Cureus}

\begin{tabular}{|l|lllllll|}
\hline Drugs & \multicolumn{2}{l}{ Sensitive } & \multicolumn{2}{l|}{ Intermediate } & \multicolumn{2}{l|}{ Resistant } \\
Type of strain & Test & Control & Test & Control & Test & Control \\
Ampicillin & 1 & - & 1 & - & 98 & 50 \\
Amikacin & 80 & 46 & 4 & 2 & 16 & 2 \\
Cotrimoxazole & 47 & - & - & - & 53 & - \\
Nitrofurantoin (only for urine isolate) & 62 & - & - & - & 3 & - \\
Cephalothin & 9 & 10 & 7 & - & 84 & 40 \\
Ceftriaxone & 28 & - & 1 & - & 71 & - \\
Ciprofloxacin/ Norfloxacin & 21 & 28 & - & - & 79 & 22 \\
Imipenem & 100 & 100 & - & - & - & - \\
\hline
\end{tabular}

TABLE 4: Antibiotic Susceptibility Patterns of Test and Control Strains of E. coli

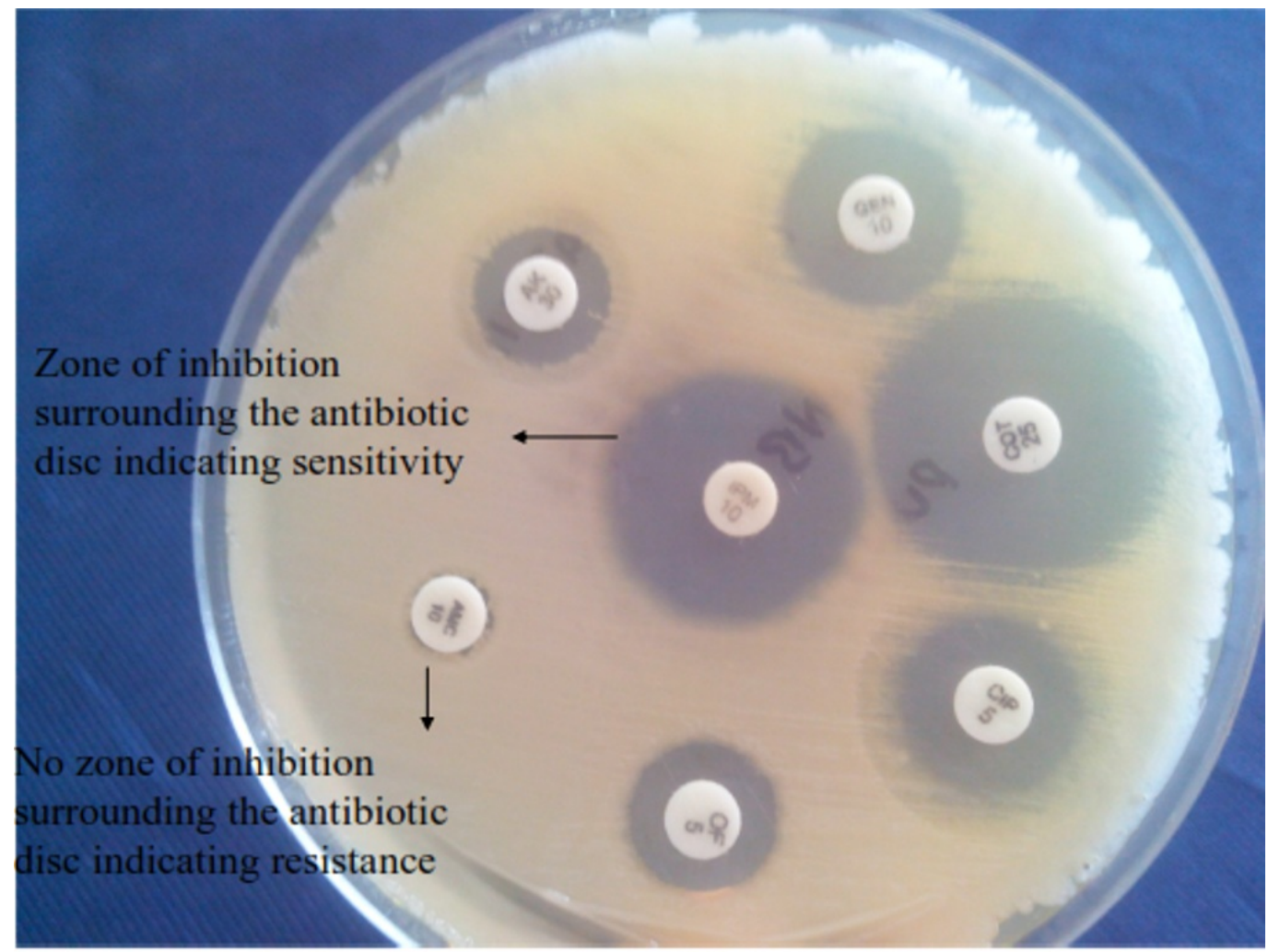

FIGURE 4: Antibiotic Susceptibility Plate Showing Zones of Clearance Surrounding Antibiotic Discs 


\section{Discussion}

Escherichia coli is a diverse group of bacteria, demonstrating variations both phenotypically and genotypically. Only $20 \%$ genetic similarity was observed between the many prevailing strains (a strain represents a subgroup within the species) of E. coli. E. coli strains are also subdivided based on the presence of surface antigens that include the somatic $\mathrm{O}$ antigen, the flagellar $\mathrm{H}$ antigen and the capsular K antigen. More than 150 serotypes of $E$. coli have been identified and related to different infectious conditions. The disease caused by a particular strain of $E$. coli depends on the type of virulence determinants it possesses as evidenced by the fact that some strains of $E$. coli cause mild diarrhea among adults and the same strains may produce a potentially life-threatening illness when they infect children/neonates. Virulence factors play an important role for Escherichia coli to colonize selectively the mucosal uro-epithelium, and starting an inflammatory reaction which helps it in proceeding from lower urinary tract to renal tissues. The capacity of $E$. coli to produce many virulence factors contributes to its pathogenicity and the ability to cause serious infections that include bacteremia and neonatal meningitis. Among controls none of the isolates exhibited all the four virulence factors and 38 (76\%) Escherichia coli isolates have not revealed any of these virulence factors. All the isolates from the test group exhibited either one or more virulence factors suggesting the fact that the ability to cause infection improves with the presence of virulence factors.

Among the various determinants of virulence in invasive strains, $\alpha$-hemolysin (HlyA), which hemolyzes red blood cells by forming pores in the erythrocyte membrane assumes significance. The frequency by which hemolytic $E$. coli strains can be isolated from patient samples increases with the severity of disease [13-14]. In the present study hemolytic activity was seen in nine percent of the cases and in none of the controls. Blanco et al. reported 32\% hemolysin production among the cases which is a contrast to the results of the present study [15]. Kausar et al. in their study noted $21 \%$ hemolytic activity among test strains [16]. Raksha et al. have reported $41.36 \%$ strains showing hemolytic activity among strains isolated from extraintestinal infections, which is way too high when compared to our study. The same study had reported six percent hemolytic activity among the control group i.e. fecal samples from apparently healthy people [8].

Cell surface hydrophobicity plays a key role in mediating bacterial adherence to mammalian cells. The crystalline surface layer 's' present on both gram-negative and gram-positive organisms plays a role in this hydrophobicity [9]. In the present study, nine percent of the strains were hydrophobic. Interestingly $10 \%$ of the control isolates too showed hydrophobicity. Blanco et al. in their research have reported $35 \%$ of isolates as demonstrating hydrophobic activity [15]. Bhat et al. reported $27.6 \%$ isolates to be hydrophobic in their study [2]. Raksha et al. in their study reported $26.4 \%$ strains demonstrating hydrophobic activity and found $10 \%$ of control strains to be hydrophobic, revealing a significant difference in statistics with regard to virulence detection [8].

Serum resistance is the property by which the bacteria resist killing by normal human serum due to the lytic action of the alternative pathway of complement system [17]. Bacterial resistance to killing by serum results from individual or combined effect of capsular polysaccharide, O polysaccharide, and surface proteins [18].

Isolates from patients with pyelonephritis, cystitis, and bacteremia were typically serum resistant whereas strains isolated from patients with asymptomatic bacteriuria were serum sensitive [18]. The serum-resistant gram-negative bacteria were found to possess a significant survival advantage in the blood during bacteremia [19]. In the present study, $93 \%$ of the isolates were resistant to serum bactericidal activity, whereas only four percent were serum resistant among control strains. The majority of the test strains which were positive for serum resistance were from urine ( 62 from a total of 65 urine samples) and pus ( 25 from a total of 29 pus 
isolates). Siegfried et al. have reported serum resistance in $68 \%$ of E. coli strains [10]. Raksha et al. in their research showed $32.7 \%$ of extraintestinal isolates and $24 \%$ of control strains to be resistant to serum bactericidal activity [8]. Our study results were comparable with studies done by Bhat et al. where they found that $86.8 \%$ of $E$. coli isolates showed serum resistance [2].

Gelatinase, an important virulence factor which is capable of hydrolyzing gelatin, collagen, and other bioactive peptides is associated with inflammation [20]. A study by Bhat et al. reported 6.9\% gelatinase production whereas the present study detected gelatinase producing ability in only two percent of the isolates [2].

The present study revealed expression of multiple virulence factors by extraintestinal E. coli isolates. Most of the serum-resistant isolates were also hydrophobic, hemolytic, and gelatinase producers. In our study, none of the isolates showed the presence of all the four virulence factors. Presence of three virulence factors was noted in one percent isolates and the presence of two virulence factors was noted among $14 \%$ isolates. Studies have indicated that although virulence of an organism cannot be accurately predicted on the basis of its measurable virulence factor phenotype, the presence of multiple virulence factors does increase the virulence of organisms.

The emergence of multidrug-resistant organisms restricts the choices for therapy for hospitalacquired infections [21]. Antibiotic susceptibility pattern was studied for all the isolates of $E$. coli. Majority of the isolates (80\%) were sensitive to amikacin, $47 \%$ were sensitive to cotrimoxazole, and $93 \%$ of urine isolates were sensitive to nitrofurantoin (total of 65 urine isolates). Resistance was observed against various commonly used antibiotics such as ampicillin, nalidixic acid, cephalothin, ciprofloxacin/norfloxacin, and ceftriaxone. The presence of multi-drug resistance may be related to the dissemination of antibiotic resistance among hospital isolates of $E$. coli. Kausar et al. in their study have reported 92\% strains as sensitive to amikacin, $85 \%$ sensitive to nitrofurantoin, 29\%-45\% sensitivity to co-trimoxazole, cephalothin, ciprofloxacin/norfloxacin, and ceftriaxone [11]. Another study done by Oteo et al. in their research reported resistance to ampicillin, cotrimoxazole, ciprofloxacin, gentamicin, and tobramycin at the rate of 59.9\%, 32.6\%, 19.3\%, 6.8\%, and 5.3\% respectively [22]. These results support the hypothesis that various virulence factors and antibiotic resistance may confer increased fitness on the part of $E$. coli to cause extraintestinal infections in humans.

\section{Conclusions}

The present study results re-establish the fact that E. coli strains are present in human, animal, and the environment and that most $E$. coli isolates are opportunistic pathogens. E. coli isolates from human extraintestinal infections have demonstrated the presence of various virulence factors which were absent in the $E$. coli strains present as commensals. E. coli has the ability to adapt and survive in humans by producing virulent factors and developing antimicrobial drug resistance. The virulence factor(s) could be selective and their expression may be related to the area of colonization.

Most virulence determinants are genetic and are phenotypically expressed only under certain conditions that include and are not limited to environmental factors and impaired host defence mechanisms. Identification of the ability of a bacterial strain to phenotypically express virulence factors and the related mechanisms could contribute to improved patient management. Since antimicrobial drug resistance is high among the E. coli strains isolated from human infections, a regular evaluation of antimicrobial susceptibility patterns of various clinical isolates and proper selection of antibiotics is warranted.

\section{Additional Information}




\section{Disclosures}

Human subjects: Consent was obtained by all participants in this study. Animal subjects: All authors have confirmed that this study did not involve animal subjects or tissue. Conflicts of interest: In compliance with the ICMJE uniform disclosure form, all authors declare the following: Payment/services info: All authors have declared that no financial support was received from any organization for the submitted work. Financial relationships: All authors have declared that they have no financial relationships at present or within the previous three years with any organizations that might have an interest in the submitted work. Other relationships: All authors have declared that there are no other relationships or activities that could appear to have influenced the submitted work.

\section{References}

1. Crichton PB: Enterobacteriaceae. Escherichia, Klebsiella, Proteus and other genera . Mackie and McCartney - Practical Medical Microbiology. Collee JG, Fraser AG, Marmion BP, Simmons A (ed): Churchill Livingstone, New York; 1996. 361-84.

2. Sharma S, Bhat GK, Shenoy S: Virulence factors and drug resistance in Escherichia coli isolated from extraintestinal infections. Indian J Med Microbiol. 2007, 25:369-373.

10.4103/0255-0857.37341

3. Picard B, Garcia JS, Gouriou S, Duriez P, Brahimi N, Bingen E, et al.: The link between phylogeny and virulence in Escherichia coli extraintestinal infection. Infect Immun. 1999, 67:546-553.

4. Ly A, Henderson J, Lu A, Culham DE, Wood JM: Osmoregulatory systems of Escherichia coli: identification of betaine-carnitine-choline transporter family member BetU and distributions of betU and trkG among pathogenic and nonpathogenic isolates. J Bacteriol. 2004, 186:296306. 10.1128/JB.186.2.296-306.2004

5. Banu A, Kabin J, Anand M: Extraintestinal infections due to Escherichia coli: an emerging issue. J Clin Diagn Res. 2011, 5:486-490.

6. Cavalieri SJ, Bohach GA, Snyder IS: Escherichia coli alpha-hemolysin: characteristics and probable role in pathogenicity. Microbiol Rev. 1984, 48:326-343.

7. Emody L, Pal T, Safonova NV, Kuch B, Golutva NK: Alpha hemolysin: an additive virulence factor in Escherichia coli. Acta Microbiol Acad Sci Hung. 1980, 27:333-342.

8. Raksha R, Srinivasa H, Macaden RS: Occurrence and characterization of uropathogenic Escherichia coli in urinary tract infections. Indian J Med Microbiol. 2003, 21:102-107.

9. Brauner A, Katouli M, Tullus K, Jacobson SH: Cell surface hydrophobicity, adherence to HeLa cell cultures and hemagglutination pattern of pyelonephritogenic Escherichia coli strains. Epidemiol Infect. 1990, 105:255-263. 10.1017/S0950268800047865

10. Siegfried L, Kmetova M, Puzova H, Molokacova M, Filka J: Virulence-associated factors in Escherichia coli strains isolated from children with urinary tract infections. J Med Microbiol. 1994, 41:127-132. 10.1099/00222615-41-2-127

11. Siegfried L, Puzova H: Response of Escherichia coli strains carrying plasmids and their plasmidless derivatives to bactericidal activity of human serum and polymorphonuclear leucocytes. Acta Microbiol Hung. 1991, 38:107-115.

12. Chatterjee B, Kulathinal S, Bhargav A, Jain Y, Kataria R: Antimicrobial resistance stratified by risk factor among Escherichia coli strains isolated from the urinary tract at a rural clinic in central India. Indian J Med Microbiol. 2009, 27:329-334. 10.4103/0255-0857.55449

13. Evans DJ, Evans DG, Höhne C, et al.: Hemolysin and $\mathrm{K}$ antigens in relation to serotype and hemagglutination type of Escherichia coli isolated from extraintestinal infections. J Clin Microbiol. 1981, 13:171-178.

14. Johnson JR, Moseley SL, Roberts PL, Stamm WE: Aerobactin and other virulence factor genes among strains of Escherichia coli causing urosepsis: association with patient characteristics. Infect Immun. 1988, 56:405-412.

15. Blanco J, Alonso M P, Gonzalez E A, Blanco M, Garabal JI: Virulence factors of bacteraemic Escherichia coli with particular reference to production of cytotoxic necrotizing factor (CNF) by P- fimbriate strains. J Med Microbiol. 1990, 31:175-183. 10.1099/00222615-31-3-175

16. Kausar Y, Chunchanur SK, Nadagir SD , Halesh LH, Chandrasekhar MR: Virulence factors, 


\section{Cureus}

serotypes and antimicrobial suspectibility pattern of Escherichia coli in urinary tract infections. Al Ameen J Med Sci. 2009, 2:47-51.

17. Leying H, Suerbaum S, Kroll H, Stahl D, Opferkuch W: The capsular polysaccharide is a major determinant of serum resistance in K-1-positive blood culture isolates of Escherichia coli. Infect Immun. 1990, 58:222-227.

18. Hughes C, Phillips R, Roberts AP: Serum resistance among Escherichia coli strains causing urinary tract infection in relation to $\mathrm{O}$ type and the carriage of hemolysin, colicin and antibiotic resistance determinants. Infect Immun. 1982, 35:270-275.

19. Donnenberg MS: Enterobacteriaceae. Mandell, Douglas, and Bennett's Principles and Practice of Infectious Diseases. Mandell GL, Bennet JE, Dolin R (ed): Churchill Livingstone, New York; 2005. 2567-2586.

20. Orskov I and Orskov F: Escherichia coli in extraintestinal infections. J Hyg camb. 1985, 95:551-575.

21. Lepelletier D, Caroff N, Reynaud A, Richet H: Escherichia coli: epidemiology and analysis of risk factors for infections caused by resistant strains. Clin Infect Dis. 1999, 29:548-552. $10.1086 / 598632$

22. Oteo J, Lázaro E, de Abajo FJ, Baquero F, Campos J, Spanish members of EARSS: Antimicrobial-resistant invasive Escherichia coli, Spain. Emerg Infect Dis. 2005, 11:546-53. 10.3201/eid1104.040699 